\title{
Flower elliptical-orbit constellation exploiting millimetre-wave radiometry and radio occultation for meteo-climatological applications
}

\author{
F. S. Marzano ${ }^{1,2}$ and D. Cimini ${ }^{2}$ \\ ${ }^{1}$ Dipartimento di Ingegneria Elettronica, Sapienza Università di Roma, Via Eudossiana 18, Rome, Italy \\ ${ }^{2}$ Centro di Eccellenza CETEMPS, Università dell'Aquila, Via Vetoio, L'Aquila, Italy
}

Received: 6 November 2009 - Revised: 1 May 2010 - Accepted: 2 May 2010 - Published: 13 July 2010

\begin{abstract}
This paper reports on the potential of combining elliptical-orbit Flower constellations with millimeter-wave radiometry and radio-occultation, a mission concept briefly named FloRad2. The advantages of flower constellation with respect to conventional orbits are discussed, including the flexibility ensuring increasing coverage with separate launches. Millimeter-wave radiometry and radio-occultation receivers provide the advantage to design fairly compact payloads that comply well with current technology of minisatellites. Millimeter-wave radiometry and radio-occultation techniques are somewhat complementary and an optimal combination of these observations results in atmospheric products with enhanced vertical and horizontal resolutions. Thus, the combination of small, light payloads employing millimeter-wave radiometry and radio-occultation with Flower elliptical-orbit constellations may result in an optimal compromise between retrieval performances and system complexity that is ideal for continued long-term missions with meteorological and climatological applications.
\end{abstract}

\section{Introduction}

The role of the atmosphere and its hydrological cycle within the Earth system is recognized to be of utmost importance. In this respect, the troposphere plays the major role as it is the atmospheric layer where water vapour, clouds and precipitation evolve within the hydrological cycle. The latter is determinant for meteorology, nowcasting, hydrology and

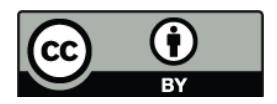

Correspondence to: F. S. Marzano

(marzano@die.uniroma1.it) climatology purposes (e.g., Giorgi and Mearns, 1999; Prabhakara et al., 2000; Pulvirenti et al., 2002; Marzano et al., 2004; Bormann et al., 2006; Faccani et al., 2007; Leroy et al., 2008).

The lower atmosphere may be observed from ground and space with remote sensors (Kidder and Vonder Haar, 1995). In-situ techniques are useful for relatively small area monitoring; their role is, however, essential for ground validation purposes. Ground-based remote sensing instrumentation has the advantage of higher spatial and temporal resolutions, but a reduced coverage. Satellite sensors, such as microwave and infrared radiometers, radars and optical imagers, can provide a large coverage especially in areas, such as oceans and remote areas, where any other observation is practically impossible (Rodgers, 1976; Schlüssel et al., 2007).

Microwave (MW) and millimeter-wave (MMW) observation of the atmosphere is becoming an appealing goal within satellite radiometry applications (e.g., Bauer and Di Michele, 2007). The major technological advantage of MMW radiometers, i.e. a system with operating frequency between 30 and $300 \mathrm{GHz}$, is the reduced size of the overall system with respect to lower-frequency sensors. On the other hand, MMW sounding can exploit window frequencies and various gaseous absorption bands around $55 \mathrm{GHz}, 118 \mathrm{GHz}$ and $183 \mathrm{GHz}$. These bands can be used to estimate temperature profiles, water vapour and cloud liquid contents and, to some extent, rainfall and snowfall for numerical weather prediction, data assimilation, climate benchmarking, hydrometeorology, nowcasting, and civil protection applications (Stoffelen et al., 2006; Rizzi et al., 2006).

Spaceborne MMW radiometers can exhibit relatively small field-of-views (FOVs), of the order of a few kilometers, for low-Earth-orbit (LEO) satellites (Kidder and Vonder

Published by Copernicus Publications on behalf of the European Geosciences Union. 
Haar, 1995). The temporal resolution of LEO platform observations remains a major drawback with respect to that of geosynchronous-Earth-orbit (GEO) satellites. An overpass about every $12 \mathrm{~h}$ for a single LEO platform (conditioned to a sufficiently large swath of the scanning MMW radiometer) may be not compatible with the typical temporal-scale variation of atmospheric fields (e.g., Marzano et al., 2004). Another technique for profiling the thermodynamic state of the Earth atmosphere from LEO satellites was demonstrated more recently (Ware et al., 1996) exploiting active limb sounding based on the radio occultation (RO) of signals emitted by Global Navigation Satellite Systems (GNSS).

A way to tackle this impasse about the temporal resolution is to draw our attention to the deployment of a constellation of satellites sensors (Kidder and Vonder Haar, 1995). The price to pay in order to push forward this solution is to keep the overall mission budget, from both an economic and engineering point of view, relatively low, satisfying at the same time the mission scientific objectives. This essentially means to design: (i) a low-weight micro-satellite platform; (ii) a light compact MMW radiometer; (iii) a launch strategy in order to deploy all platforms with only one launcher; (iv) an adaptive retrieval scheme able to exploit available sensor data. Another degree of freedom that a satellite constellation may open, with respect to a single-platform mission, is the design of an optimal space-time coverage for atmospheric monitoring and a reconfigurable and expandable spaceborne topology (Mortari et al., 2005).

In this work we will discuss the basic concepts of the FloRad2 small-mission, aimed at designing a constellation of mini-satellite deploying a MMW radiometer and GNSS $\mathrm{RO}$ receiver for sounding the atmospheric thermodynamical state and hydrometeors content. The name FloRad2 arises from "FLOwer constellation of millimeter-wave RADiometers and RADio occultation receivers" and builds on the FloRad project proposing the concept of synergy between Flower constellation theory and millimeter-wave radiometry (Marzano et al., 2008, 2009). The mission requirements will be described together with payload and satellite design principles. The potential combined use of millimeter-wave radiometry and radio-occultation will also be discussed.

\section{FloRad2 mission requirements}

The FloRad2 mission is devoted to atmospheric remote sensing (Marzano et al., 2009). In particular, the goal is to sense the troposphere in terms of its thermal and hydrological properties. Specifically, the FloRad2 mission is aimed at the measurement of: millimeter-wave brightness temperature, temperature profile, water-vapour integrated content and profile, cloud water integrated content and profile, rain water integrated content and profile and snow integrated content and profile. The major scientific applications of FloRad2 are oriented to: (i) Regional numerical weather Prediction (RP); (ii) Global numerical weather Prediction (GP); (iii) Atmospheric nowcasting (NC); (iv) Hydrology (HL); (v) Climatology (CL).

Data assimilation for numerical weather prediction nowadays requests the provision of accurate radiance measurements to be ingested into numerical models instead of retrieved atmospheric products (e.g., Bormann et al., 2006; Faccani et al., 2007). Microwave and millimeter-wave brightness temperatures are of utmost importance due to their relation with atmospheric microphysics and cloud formation (e.g., Bauer and Di Michele, 2007). Time sampling is not crucial for data assimilation, but the temporal bias of measurements (such as that derived from sun-synchronous satellites) may affect the assimilation procedure. Regional models tend to uses regional boundary conditions and satellite data at regional scale, whilst global models are able to assimilate satellite data on a global scale whenever and wherever available (Dudhia, 1993). The Mediterranean basin represents a special target area for hydro-meteorological applications being at the confluence of African air masses and Atlantic air masses coupled with a large internal water surface.

Hydrology applications are oriented to exploit atmospheric products, derived from ground-based precipitation retrievals (e.g., Pulvirenti et al., 2002). The knowledge of water effects at ground at relatively high resolution is essential to initialize numerical distributed models in order to predict river-basin run off (Wentz et al., 2007). Depending on the hydrologic features and topography, the timeliness of precipitation inputs plays a major role to predict river run-off.

Nowcasting applications impose stringent requirements on the revisit time at the target regional scale. The latter is the major drawback of LEO satellites as, for a single platform with a wide-swath sensor, the revisit time cannot be less than about $12 \mathrm{~h}$. Blending techniques aimed at combining LEO MW data and GEO IR data need frequent updates of MW and MMW measurements to calibrate IR-based geostationary observations (Marzano et al., 2004). Moreover, data delivery delay time to operational centres for environmental control and civil protection must be relatively short in order to allow the full exploitation of satellite products.

Meteo-climatological purposes push forward a spatial coverage as large as possible over the globe and a long-term observations and data storage (Goody et al., 2002). This means that payload data acquisition must be performed not only over the target region, but a quasi-global scale even though with different characteristics. However, the increasing importance of regional climate models is testified by recent literature which identifies regional features of climate which can be resolved by ad hoc observations from ground and satellites (Giorgi and Mearns, 1999). Several regional climate models are focused on the European scale, including the continental land, the Mediterranean basin and the Baltic sea which tend to modify global circulation and ocean-atmosphere coupling even at longer time scales (Giorgi and Mearns, 1999). Finally, for meteo-climatological 
Table 1. FloRad2 mission scientific requirements.

\begin{tabular}{|c|c|c|c|}
\hline PRODUCTS & REQUIREMENTS & $\begin{array}{c}\text { Threshold } \\
\text { value }\end{array}$ & $\begin{array}{c}\text { Goal } \\
\text { value }\end{array}$ \\
\hline $\begin{array}{l}\text { Millimeter-wave brightness } \\
\text { temperature }[\mathrm{K}]\end{array}$ & $\begin{array}{l}\text {-Accuracy } \\
\text {-Stability } \\
\text {-Horizontal resolution (nadir-equivalent) } \\
\text {-Temporal resolution (revisit time at } 75 \% \text { time percentile) } \\
\text {-Delivery delay time (nowcasting application) }\end{array}$ & $\begin{array}{l}1 \mathrm{~K} \\
0.1 \mathrm{~K} / \text { year } \\
<25 \mathrm{~km} \\
<3 \mathrm{~h} \\
<2 \mathrm{~h}\end{array}$ & $\begin{array}{l}0.5 \mathrm{~K} \\
0.01 \mathrm{~K} / \text { year } \\
<15 \mathrm{~km} \\
<2 \mathrm{~h} \\
<1 \mathrm{~h}\end{array}$ \\
\hline $\begin{array}{l}\text { Temperature vertical profile } \\
\text { [K] }\end{array}$ & $\begin{array}{l}\text {-Accuracy (over sea) } \\
\text {-Horizontal resolution (nadir-equivalent) } \\
\text {-Temporal resolution (revisit time at } 75 \% \text { time percentile) } \\
\text {-Delivery delay time (nowcasting application) }\end{array}$ & $\begin{array}{l}<2 \mathrm{~K} \\
<25 \mathrm{~km} \\
<3 \mathrm{~h} \\
<2 \mathrm{~h}\end{array}$ & $\begin{array}{l}<1 \mathrm{~K} \\
<15 \mathrm{~km} \\
<2 \mathrm{~h} \\
<1 \mathrm{~h}\end{array}$ \\
\hline $\begin{array}{l}\text { Water vapor integrated } \\
\text { content }\left[\mathrm{kg} / \mathrm{m}^{2}\right] \text { and vertical } \\
\text { profile }\left[\mathrm{g} / \mathrm{m}^{3}\right]\end{array}$ & $\begin{array}{l}\text {-Accuracy for integrated content (over sea) } \\
\text {-Accuracy for content profile (over sea) } \\
\text {-Horizontal resolution (nadir-equivalent) } \\
\text {-Temporal resolution (revisit time at } 75 \% \text { time percentile) } \\
\text {-Delivery delay time (nowcasting application) }\end{array}$ & $\begin{array}{l}<3 \mathrm{~kg} / \mathrm{m}^{2} \\
<1.5 \mathrm{~g} / \mathrm{m}^{3} \\
<25 \mathrm{~km} \\
<3 \mathrm{~h} \\
<2 \mathrm{~h}\end{array}$ & $\begin{array}{l}<2 \mathrm{~kg} / \mathrm{m}^{2} \\
<1 \mathrm{~g} / \mathrm{m}^{3} \\
<15 \mathrm{~km} \\
<2 \mathrm{~h} \\
<1 \mathrm{~h}\end{array}$ \\
\hline $\begin{array}{l}\text { Cloud water integrated } \\
\text { content }\left[\mathrm{kg} / \mathrm{m}^{2}\right] \text { and profile } \\
{\left[\mathrm{g} / \mathrm{m}^{3}\right]}\end{array}$ & $\begin{array}{l}\text {-Accuracy for integrated content (over sea) } \\
\text {-Accuracy for content profile (over sea) } \\
\text {-Horizontal resolution (nadir-equivalent) } \\
\text {-Temporal resolution (revisit time at } 75 \% \text { time percentile) } \\
\text {-Delivery delay time (nowcasting application) }\end{array}$ & $\begin{array}{l}<0.5 \mathrm{~kg} / \mathrm{m}^{2} \\
<0.5 \mathrm{~g} / \mathrm{m}^{3} \\
<25 \mathrm{~km} \\
<3 \mathrm{~h} \\
<2 \mathrm{~h}\end{array}$ & $\begin{array}{l}<0.1 \mathrm{~kg} / \mathrm{m}^{2} \\
<0.05 \mathrm{~g} / \mathrm{m}^{3} \\
<15 \mathrm{~km} \\
<2 \mathrm{~h} \\
<1 \mathrm{~h}\end{array}$ \\
\hline $\begin{array}{l}\text { Rain integrated content } \\
{\left[\mathrm{kg} / \mathrm{m}^{2}\right], \text { rates }[\mathrm{mm} / \mathrm{h}] \text { and }} \\
\text { profile }\left[\mathrm{g} / \mathrm{m}^{3}\right]\end{array}$ & $\begin{array}{l}\text {-Accuracy for integrated content (over sea) } \\
\text {-Accuracy for content profile (over sea) } \\
\text {-Horizontal resolution (nadir-equivalent) } \\
\text {-Temporal resolution (revisit time at } 75 \% \text { time percentile) } \\
\text {-Delivery delay time (nowcasting application) }\end{array}$ & $\begin{array}{l}<0.5 \mathrm{~kg} / \mathrm{m}^{2} \\
<0.5 \mathrm{~g} / \mathrm{m}^{3} \\
<25 \mathrm{~km} \\
<3 \mathrm{~h} \\
<2 \mathrm{~h}\end{array}$ & $\begin{array}{l}<0.1 \mathrm{~kg} / \mathrm{m}^{2} \\
<0.1 \mathrm{~g} / \mathrm{m}^{3} \\
<15 \mathrm{~km} \\
<2 \mathrm{~h} \\
<1 \mathrm{~h}\end{array}$ \\
\hline $\begin{array}{l}\text { Snow integrated content } \\
{\left[\mathrm{kg} / \mathrm{m}^{2}\right], \text { rates }[\mathrm{mm} / \mathrm{h}] \text { and }} \\
\text { profile }\left[\mathrm{g} / \mathrm{m}^{3}\right]\end{array}$ & $\begin{array}{l}\text {-Accuracy for integrated content (over sea) } \\
\text {-Accuracy for content profile (over sea) } \\
\text {-Horizontal resolution (nadir-equivalent) } \\
\text {-Temporal resolution (revisit time at } 75 \% \text { time percentile) } \\
\text {-Delivery delay time (nowcasting application) }\end{array}$ & $\begin{array}{l}<0.5 \mathrm{~kg} / \mathrm{m}^{2} \\
<0.5 \mathrm{~g} / \mathrm{m}^{3} \\
<25 \mathrm{~km} \\
<3 \mathrm{~h} \\
<2 \mathrm{~h}\end{array}$ & $\begin{array}{l}<0.1 \mathrm{~kg} / \mathrm{m}^{2} \\
<0.1 \mathrm{~g} / \mathrm{m}^{3} \\
<15 \mathrm{~km} \\
<2 \mathrm{~h} \\
<1 \mathrm{~h}\end{array}$ \\
\hline
\end{tabular}

applications radiometric accuracy and stability need to be carefully considered as well as its traceability to the International System (SI) standards for ground and on-board sensor calibration (Leroy et al., 2008).

From an international space agency point of view, there are several plans to exploit satellite synergies in terms of Earth observations and deploy atmospheric remote sensing constellations. In particular, the Global Precipitation Measurement (GPM) mission represents a major international effort within satellite meteorology (Hou et al., 2008). The GPM primary (or mother-ship) satellite will provide detailed and accurate measurements of the three-dimensional distribution of precipitation and its associated latent heat release for most rainfall regimes around the globe, by carrying a Dual-frequency Precipitation Radar (DPR) in addition to a microwave radiometer, the GPM Microwave Imager (GMI). The constellation of drone satellites, on the other hand, will provide the temporal sampling that is required for most precipitation studies and applications. Another major example of cooperation is the so called A-Train which is a constellation of 6 satellites (i.e., Aqua, Aura, CloudSat, CALIPSO, PARASOL e OCO) flying in a close relative orbital positions (Stephens et al., 2002).

A major source to identify FloRad2 scientific requirements for hydro-meteo-climatological applications is the
EUMETSAT Post-EPS (Post-European Polar System) program. EUMETSAT, within the Post-EPS plans after 2020, has recently accomplished a mission requirement document (MRD) to rank the most urgent future missions among 21 options (Schlüssel et al., 2007). The result of this comparative analysis indicates that, after the high-resolution infrared sounding, MW sounding is at the second place before scatterometry, visible-infrared imaging and MW imaging. Moreover, a related output of this Post-EPS exercise was the list of observation or user requirements (independently from cost and technology issues) for 4 important applications such as global numerical weather prediction (NWP), regional NWP, nowcasting and climate monitoring (Stoffelen et al., 2006; Rizzi et al., 2006). In particular, requirements in terms of accuracy, spatial resolution, temporal resolution and datarelease time, were sub-divided in threshold, breakthrough and objective requirements.

From previous considerations, the general scientific requirements of the FloRad2 mission are listed in Table 1, adopting the previously introduced requirement identification.

It is worth noting that in Table 1:

- for each user requirement, 2 values are specified, to be intended the first as a "Threshold" value (the upper limit 
value of the requirement above which the mission objectives are critically descoped) and the second as a "Goal" value (the ideal value of the requirement around which the mission objectives are fully realized).

- the product "vertical profiles" are not characterized by a quantitative requirement on the vertical resolution as a passive sounder is not able to provide a definite resolution such as an active system. The vertical resolution of a passive sounder is heavily dependent on the number of frequencies as it exploits the frequency diversity to gain a resolved range, but at the same time this resolution may be affected by the observed scenario as it modifies the so called weighting functions. In this respect, the vertical domain of the atmospheric products has to be referred to altitudes less than $15 \mathrm{~km}$.

- the term "nadir-equivalent" is used to indicate the linear field-of-view (FOV) resolution for conical scan radiometers when the antenna is looking at nadir.

- the "delivery delay time", that is the time needed to process FloRad2 raw data from the satellite acquisition to the distribution to end-users, is specified only for the nowcasting application as it is the more stringent requirement. For the other applications, this requirement may be relaxed as appropriate.

From the analysis of previous user requirements and previous considerations, the FloRad 2 mission driving concepts are primarily based on the:

- identification of compact and light-weight millimeterwave radiometers as the best payload compromise to provide the required products in terms of radiances and atmospheric parameters;

- design of a micro (or mini) spacecraft, compatible with the payload and the launcher, characterized by a relatively low weight, reduced power consumption and compact sizes;

- exploitation of a satellite constellation to easily increase the revisit time, trying to use a proper number of small satellite platforms;

- a quasi-global coverage with a regional scale target area over the Mediterrannean sea and a continental-scale target area over Europe;

- compatibility with small-class launchers such as VEGA and legacy with respect to previous meteorological satellite missions;

- complementarity with respect to international space agency plans in the field of hydro-meteo-climatic applications.

\section{Elliptical-orbit constellation design}

The FloRad2 small-mission is based on the Flower Constellation concept within a "pseudo-geostationary" scale framework (Mortari et al., 2005; Marzano et al., 2009). In a previous study we analyzed the feasibility of designing a Flower Constellation (FC) with 3 mini-satellites at relative high apogee around $1200 \mathrm{~km}$ (Marzano et al., 2009). This solution envisaged 3 mini-satellites but turned out to be problematic in terms of launch strategy. A better option would be a single launch deploying all 3 platforms by exploiting a Hohmann manoeuvres (Larson and Wertz, 1999). This launch with a transfer of the payload to about $2000 \mathrm{~km}$ would require about 125 days for a relative drift of $120^{\circ}$ and about 220 days for a relative drift of $240^{\circ}$. If the first satellite can be deployed into its elliptical orbit during the launcher's descent, the deployment of a 3-satellite constellation should take about 7 months.

Indeed, the capability of current launchers is a critical item especially when dealing with 3 mini-satellites. A critical factor is the deployment time and the propellant needed to perform all manoeuvres. A more conservative strategy would be to deploy 2 mini-satellites with one launch in a single orbital plane without needing orbital manoeuvres. The full FC might be completed following an incremental concept by performing successive launches of another 2 mini-satellites into FC pre-defined orbital planes.

The optimal design of a FC is a complex task. Further constraints on FC design come from the sensor specifications, in particular the orbit height range and sensor swath (which condition the spatial resolution and observation repeat time). The orbit height has been set within the range $650-1270 \mathrm{~km}$ and sensor swath to about $2500 \mathrm{~km}$ (depending on the scanning system here fixed to $\pm 50^{\circ}$ around the antenna boresight), in agreement with the previous study (Marzano et al., 2009). Another major concern is the choice of the inclination angle $i$ which might be chosen either to be a generic freedom parameter or to satisfy sun-synchronicity or to keep a constant perigee argument by imposing the orbit inclination angle $i=63.4^{\circ}$. Indeed, a safety constraint might be also considered: when launching from specific sites the inclination must be chosen to avoid risks to overpass highly populated area.

In order to extend previous analyses, the design of the FC has been focused on the incremental feature concept by analyzing the following configurations:

(1) An incremental FCs at $i=63.4^{\circ}$, having Moderately Elliptical orbits with perigee/apogee ratio equal to about $650 / 1270 \mathrm{~km}$, with either 2 satellites (IFC-ME2) or 4 satellites equally distributed in 2 different orbit planes (IFC-ME4) or 6 satellites equally distributed in 3 different orbit planes (IFC-ME6);

(2) Walker constellation of Circular Orbits (WK-CO6) with 6 mini-satellites in different orbital planes with $i=63.4^{\circ}$, 


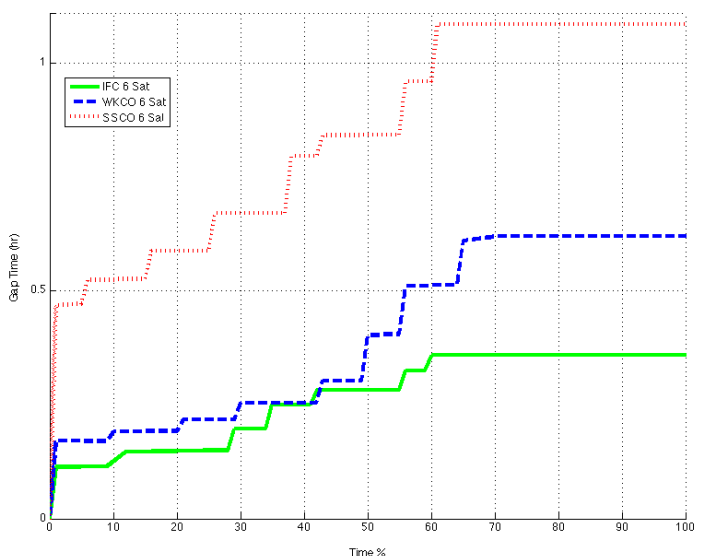

Fig. 1. Gap-time cumulative density function (CDF) for IFC with 6 satellites (IFC-ME6), WK-CO with 6 satellites (WK-CO6) and SS$\mathrm{CO}$ with 6 satellites (SS-CO6) constellations for the Regional Scale European (RSE) area.

following the design concept of Walker (having the same "average distance" from the Earth of the FC, $1060 \mathrm{~km})$

(3) Sun-Synchronous Circular Orbit (SS-CO6) constellation with 6 mini-satellites equally distributed along the same orbit plane at an altitude of about $1000 \mathrm{~km}$.

Two target regions of interest have been identified: (i) the Mediterranean Scale Basin (MSB) windows, defined between $25^{\circ} / 45^{\circ}$ latitude and $-10^{\circ} / 35^{\circ}$ longitude (this area is larger than the corresponding one used by Marzano et al., 2009); (ii) the Regional Scale European (RSE) window, delimited by the following latitude/longitude corners, respectively: $23^{\circ} /-10^{\circ}, 64^{\circ} \%-40^{\circ}, 64^{\circ} / 66^{\circ}$ and $23^{\circ} / 36^{\circ}$ (this area is identical to that used by Marzano et al., 2009). As a metric of space-time coverage we have again adopted the targetarea revisit time interval or gap-time $\Delta T_{\mathrm{rev}}$ as the time interval between two satellite overpasses over the target area, counted when the sensor swath of any constellation satellite intersects the target area. In order to compare the various satellite constellations, we have compared them in terms of the cumulative distribution function (CDF).

Figure 1 shows the gap-time CDF for IFC-ME6 and WKCO6 and SS-CO-6 constellations for the RSE area. The deployment of 6 mini-satellites with a large swath sensor enables to get revisit time gaps less than $1 \mathrm{~h}$, almost comparable to a geostationary platform. It can be noticed how FC provides better revisit time performance for every time percentage with respect to WK one.

The incremental features of FCs can be appreciated in Fig. 2 which shows the comparison among the gap-time CDFs for IFC-ME2, IFC-ME4 and IFC-ME6 constellations for the RSE area. As shown in the figures, IFC becomes very efficient since the second batch of satellites are operative (IFC-ME4); as a matter of fact revisit time interval

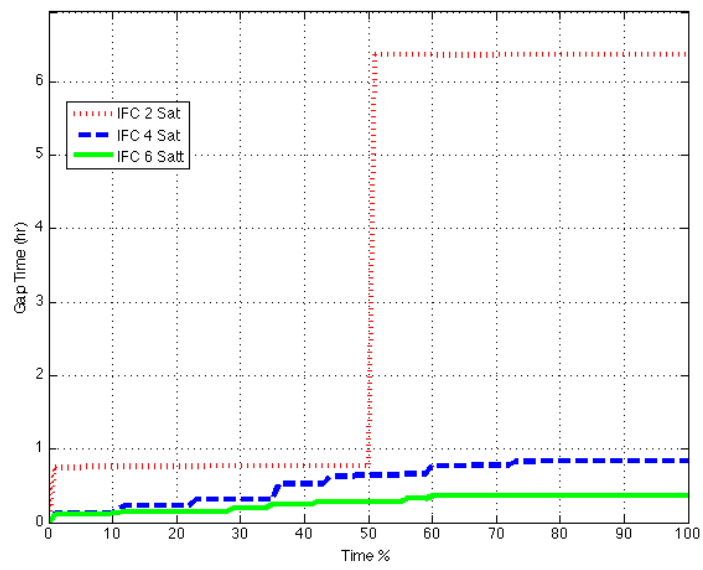

Fig. 2. Comparison of the gap-time CDFs for IFC with 2 satellites (IFC-ME2), IFC with 4 satellites (IFC-ME4) and IFC with 6 satellites (IFC-ME6) constellations the MSB area.

performance reaches a very high level, being lower than $1 \mathrm{~h}$ for $100 \%$ of the total time for the MSB window.

\section{Millimeter-wave radiometer payload}

Atmospheric monitoring is a major goal of current and future missions. In this context MW and MMW radiometry plays a relevant role due to its capability to sound through clouds and to detect precipitation (e.g., Bauer and Di Michele, 2007). Examples of well-known MW radiometers are the Advanced Microwave Sounding Unit (AMSU) and Microwave Humidity Sounder (MHS) aboard NOAA and MetOp satellites and the Special Sensor Microwave Imager Sounder (SSM/IS) aboard DMSP satellites (Schlüssel et al., 2007).

The impact of MW and MMW radiometer data assimilation into numerical weather prediction (NWP) has been shown to reduce the prediction error to more than $50 \%$ and $15 \%$ in the Southern and Northern Hemisphere, respectively (using the geopotential height till to 3 day-range) (Bormann et al., 2006). This is quite impressive when compared with infrared (IR) sensors, such as High Resolution Infrared Sounder (HIRS) whose error reduction is less than 5\%: this is explained considering that more than $85 \%$ of HIRS fieldof-views cannot be used in NWP due to cloud contamination.

The selection of MMW radiometric frequencies is based on FloRad feasibility study and on EUMETSAT reports on the same topics (Bauer and Di Michele, 2007; Marzano et al., 2009). A radiometer, with imaging and sounding capability, has to exploit window and absorption frequencies, respectively. From the analysis of the user requirements of Table 1, we have concluded that:

- the use of the $89-\mathrm{GHz}$ window frequency is essential for cloud and precipitation imaging; moreover, it is the frequency implemented in most current and future radiometers such as AMSU, SSMI/S and MHS; 
Table 2. FLOMIS radiometer configurations (H: Horizontal Pol.; V: Vertical Pol.)

\begin{tabular}{ll}
\hline Name & FLOMIS frequency channels \\
\hline MHS-like & 89 V GHz, 166.0 GHz, 183.31 V $\pm 1.0 \mathrm{GHz}$, \\
& $183.31 \mathrm{~V} \pm 3.0 \mathrm{GHz}, 190.3 \mathrm{~V} \mathrm{GHz}$ \\
MHTS1 & $89 \mathrm{H} \mathrm{GHz}, 89 \mathrm{~V} \mathrm{GHz}, 118.75 \mathrm{~V} \pm 0.7 \mathrm{GHz}$, \\
& $118.75 \mathrm{~V} \pm 2.1 \mathrm{GHz}, 118.75 \mathrm{~V} \pm 3.0 \mathrm{GHz}$, \\
& $183.31 \mathrm{~V} \pm 1.0 \mathrm{GHz}$, \\
& $183.31 \mathrm{~V} \pm 3.0 \mathrm{GHz}, 183.31 \mathrm{~V} \pm 7.0 \mathrm{GHz}$, \\
MHTS2 & $89 \mathrm{H} \mathrm{GHz}, 89 \mathrm{~V} \mathrm{GHz}, 118.75 \mathrm{~V} \pm 0.7 \mathrm{GHz}$, \\
& $118.75 \mathrm{~V} \pm 3.0 \mathrm{GHz}, 183.31 \mathrm{~V} \pm 1.0 \mathrm{GHz}$, \\
& $183.31 \mathrm{~V} \pm 3.0 \mathrm{GHz}, 190.3 \mathrm{~V} \mathrm{GHz}, 229.0 \mathrm{H} \mathrm{GHz}$ \\
MHTS+ & $89 \mathrm{H} \mathrm{GHz}, 89 \mathrm{~V} \mathrm{GHz}, 118.75 \mathrm{~V} \pm 0.7 \mathrm{GHz}$, \\
& $118.75 \mathrm{~V} \pm 2.1 \mathrm{GHz}, 118.75 \mathrm{~V} \pm 3.0 \mathrm{GHz}$, \\
& $166.0 \mathrm{~V} \mathrm{GHz}, 183.31 \mathrm{~V} \pm 1.0 \mathrm{GHz}$, \\
& $183.31 \mathrm{~V} \pm 3.0 \mathrm{GHz}, 190.3 \mathrm{~V} \mathrm{GHz}, 229.0 \mathrm{H} \mathrm{GHz}$ \\
\hline
\end{tabular}

- the use of the 118-GHz oxygen absorption band can be theoretically used for temperature profiling and cloud imaging, even though with a reduced accuracy with respect to the use of the $50 / 60 \mathrm{GHz}$ oxygen absorption band;

- the use of the $183-\mathrm{GHz}$ water-vapour band is very well suited for humidity profiling, even though the boundary layer of the lower troposphere is sounded with less accuracy as shown by MHS (Arriaga, 2000),

- the use of the window frequency at $229 \mathrm{GHz}$ is very well suited for cirrus cloud detection and much more effective than the $157 \mathrm{GHz}$ in this respect present in MHS (Sreerekha et al., 2008).

Due to its foreseen scanning capability, the FloRad2 MMW payload has been named FLOMIS, i.e. FLORad Millimeterwave Imaging. Table 2 lists the frequency set, deduced from a previous Entropy-Reduction based analysis (Marzano et al., 2010). Four configurations have been considered: (i) MHS-like resembles the 5-channel set available on MHS; (ii) MHTS1 (Microwave Humidity and Temperature Sounder-1) includes in addition another polarization at $89 \mathrm{GHz}$ and two channels around the $118 \mathrm{GHz}$ oxygen line; (iii) MHTS2 is as MHTS1 but deploys the $229 \mathrm{GHz}$ channel instead of the $166 \mathrm{GHz}$; (iv) MTHS+ merges both MHTS1 and MHTS2 configurations and also adds one more channel at $166 \mathrm{GHz}$. Note that in all configurations we have included the $166 \mathrm{GHz}$ channel, instead of the $157 \mathrm{GHz}$, since there are indications that higher frequency channel may give better performances than the $157 \mathrm{GHz}$ presently on MHS (Bauer and Di Michele, 2007). For this case study analysis, a conical scan at $53^{\circ}$ incidence angle has been supposed with a uniform channel field-of-view equal to about $25 \mathrm{~km}$.
The retrieval of the tropospheric parameters has been performed by means of a statistical inversion algorithm: for our purposes, we have employed a polynomial regression model of third order in $\mathrm{T}_{B}$ both for profile and integrated content retrieval.

The inverse method has been trained and tested dividing the whole dataset into two groups (with a sample ratio 10:1) according to the different background type (sea and land). The choice of the training set was driven by representing better than a climatological mean the a priori information we intend to use in the operational retrieval (one-dimensional variational retrieval method). It is worth reminding that random noise was added to simulated $p$-polarized $\mathrm{T}_{B p}$ accounting for instrumental noise and a simple emissivity model was used in computing the upwelling brightness temperatures (see Marzano et al., 2009 for details).

Figure 3 shows the profiles of root mean square error (RMSE) for atmospheric variables retrieved from MR over sea and land background from simulated MHTS+ observations (see Marzano et al., 2009 for details). The corresponding variability, expressed as standard deviation over the whole set, is also shown in order to indicate the information gain due to the use of radiometric observations. The error uncertainty for temperature retrieval is less than $1 \mathrm{~K}$ over sea and less than $2 \mathrm{~K}$ over land (neglecting uncertainties related to surface emissivity). Humidity profiles can be retrieved with an error standard deviation increasing for lower altitudes and less $1 \mathrm{~g} / \mathrm{m}^{3}$ over sea and $1.5 \mathrm{~g} / \mathrm{m}^{3}$ over land. Non-precipitating liquid and ice profiles are again difficult to be retrieved both over land and sea, but better results are obtained for rain and snow retrieval with errors less than $0.03 \mathrm{~g} / \mathrm{m}^{3}$ and $0.02 \mathrm{vg} / \mathrm{m}^{3}$, respectively, both over land and sea.

The results of this numerical analysis may give an idea of the expected performances of the FloRad2 mission products. A comparison with other comparable and current measurements are shown in a previous paper (Marzano et al., 2009). For NWP data assimilation purposes, FloRad2 brightness temperature measurements can be considered to be a mission product. In this respect, the spaceborne exploitation of the 118-GHz band might represent a unique opportunity as it has never been tested in space, even though it is foreseen for Post-EPS (Schlüssel et al., 2007). The same consideration applies to the $229-\mathrm{GHz}$ band whose role has been already discussed.

\section{Synergy with radio-occultation observations}

The radio occultation method for obtaining atmospheric soundings is summarized by Kursinski et al. (1997). The GNSS radio-occultation technique measures the profile of the refractive properties of the atmosphere by observing the timing delay of GNSS signals induced by the atmosphere as the ray-path descends toward the Earth's surface in a limb 

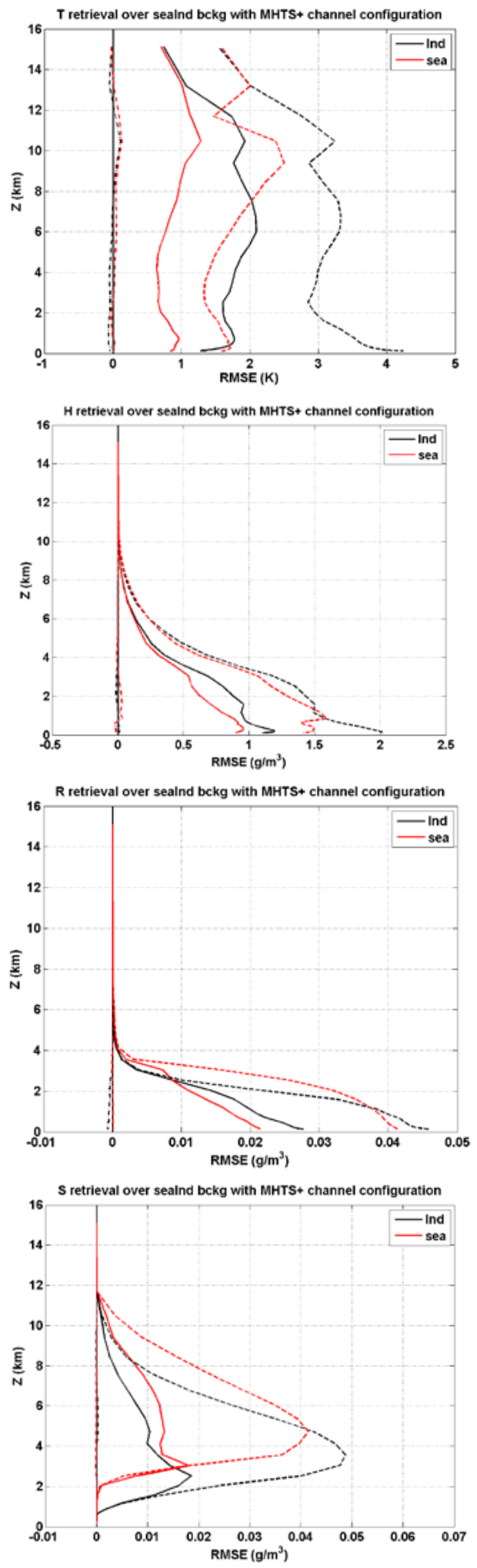

Fig. 3. Profiles of root mean square error (RMSE) for atmospheric variables retrieved over sea (red) and land (black) background (with $T$ : temperature; $H$ : humidity; $R$ : rain; $S$ : snow). The corresponding variability (standard deviation over the whole set) is also shown (dashed). sounding geometry. The index of refraction is directly related to pressure, temperature, and water vapor concentration such that the refractive index can be processed to obtain profiles of these atmospheric variables.

The accuracy of RO retrievals is estimated better than $1 \mathrm{~K}$ for temperature and better than $10 \%$ (or $0.2 \mathrm{~g} / \mathrm{kg}$ ) for humidity profiles (Vespe et al., 2009). Comparisons between profiles retrieved from different $\mathrm{RO}$ have verified the expected high sounding precision (Antes et al., 2008). The vertical resolution of the derived profiles ranges from about $0.3 \mathrm{~km}$ in the lower troposphere to $1-3 \mathrm{~km}$ in the higher atmosphere, but with the use of advanced inversion methods it can be as high as $60 \mathrm{~m}$ (Gorbunov et al., 2004).

The GNSS RO-retrieved profiles start at some $40 \mathrm{~km}$, while the penetration down to the Earth's surface depends on a number of factors, such as inversion algorithms, receiver signal tracking algorithms, vertical structure of the refractivity profile, and receiver antenna gain. Conventional tracking of the GNSS RO signal in many cases does not allow penetration below the top of the atmospheric boundary layer (ABL). A more sophisticated processing, called open-loop (OL) tracking, allows a deeper penetration in the lower atmosphere (Sokolovskiy et al., 2006). The implementation of OL tracking applied to the Constellation Observing System for Meteorology, Ionosphere, and Climate (COSMIC) mission, increased significantly the probability of penetration in the lower $2 \mathrm{~km}$ with a atmospheric refractivity bias less than $1 \%$ with respect to model. It was estimated that about $70 \%$ of the COSMIC soundings penetrate below $1 \mathrm{~km}$ over the sea surface in the tropics, with about $90 \%$ reaching this depth at high latitudes (Antes et al., 2008).

RO payloads are basically composed by a receiver, a RO antenna, and a navigation antenna; current technology, as for example the Italian Radio Occultation Sounder of the Atmosphere (ROSA) onboard the Indian OCEANSAT-2 satellite, allows relative small dimensions $\left(\sim 0.1 \mathrm{~m}^{3}\right)$ and low weight (17 kg) (Vespe et al., 2009).

High level of complementarity is seen for MMW radiometry and active GNSS radio occultation observations. RO soundings offers high vertical resolution but, despite the fact that they are referred to a point (the tangent point), they are representative of the path in which the ray bending takes place, roughly $300 \mathrm{~km}$. On the other hand passive microwave observations may offer higher horizontal resolution $(10-20 \mathrm{~km})$ with rather poor vertical resolution, as previously discussed. In addition, MMW radiometry profiles are more sensitive to the higher troposphere, due to their weighting functions, while GNSS RO with OL tracking is able to profile down to the ABL. Therefore, an optimal combination of the two techniques may provide the same horizontal resolution of the MMW radiometry but with enhanced vertical resolution. In addition, unlike microwave radiance, GPS RO is negligibly affected by the presence of clouds and precipitation, and thus RO observation can be used as ancillary 
information in the variational retrieval of precipitation from MMW radiometry.

Note that the GNSS RO offers an ideal method for benchmarking the climate system (Leroy et al., 2006). In fact, the technique uses a measurement of frequency shift against a time standard and is therefore simply traceable to international standards. Moreover, GNSS occultation offers an accurate measurement of geopotential heights on constant pressure surfaces throughout most of the troposphere and stratosphere and thus offers the opportunity to directly observe thermal expansion of the troposphere in response to forcing. Finally, the infrastructure exists and will keep existing in the Global Positioning System (GPS) and the future Galileo constellations. As a consequence, the accuracy of each occultation is independently testable into the indefinite future and can be easily replicated by any observing community.

Because of their traceability, GNSS RO observations not only concur to establishing a climate record, but they can also be very useful for assessing the quality of the MMW observations, as demonstrated by Ho et al. (2007) and Antes et al. (2008). In fact, MMW observations are subject to in-orbit drift errors and intersatellite biases, even with continuous inorbit calibration. Thus, an independent dataset, free of inorbit drift errors and satellite-to-satellite biases, is desirable to intercalibrate measurements from different satellite missions (Goody et al., 2002). Therefore, a subset of MMW and GNSS RO observations match-ups can be used for independent and external calibration of the MMW with respect to a technique traceable to international standards.

In summary, there few reasons for exploiting the synergy between MMW radiometry and GNSS RO; due to the acceptable dimension and weight of GNSS RO receiver and antennas, it seems feasible to add such a system to the Flo$\operatorname{Rad} 2$ mission and concept. The FloRad2 RO Sounder payload has been named FLOROS.

\section{Space and ground segments}

The FloRad2 mission architecture is composed of the following segments (Marzano et al., 2008):

- the space segment devoted to provide scientific data for the mission lifetime of 3 years;

- the ground segment responsible for data acquisition, mission operation and control of the entire constellation and the first processing level (until Level 1B);

- the user segment devoted to the generation and dissemination of the geo-physical products to the users.

The satellite configuration, based on the PRIMA Platform Service Module, presents the following features and advantages (Marzano et al., 2008):

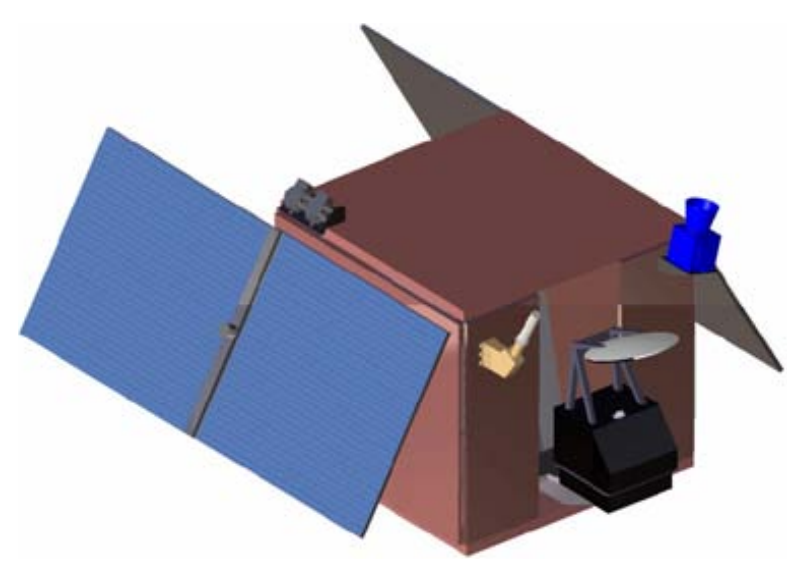

Fig. 4. Sketch of the PRIMA spaceborne platform with the frontend FLOMIS radiometer (adapted from Marzano et al., 2008)

- the module architecture allows for the accommodation of all the Platform and Instrument units, also giving a certain margin of growth in terms of units number/volume;

- the mechanical architecture is drawn by a fully qualified model with minor modifications induced by the instrument accommodation;

- the lateral surfaces are adequate in number and sizes to install the S/A wings and to radiate the internally generated heat;

- the satellite size and external layout is suitable for launch either as single satellite and for a two satellites in stacked configuration. This allows for the maximum flexibility in the launch strategy.

The choice of this non-sun-synchronous orbit has induced to discharge low cost standard platform because the solar incidence angle on the platform is not constant and requires a devoted platform meeting the thermal and power sub-system requirements. The solution is PRIMA S, a three-axes stabilised platform with autonomous capability to acquire the final orbit and a pointing accuracy better than $0.03^{\circ}$ on each axis (using a star sensor) and derived from the PRIMA platform (Marzano et al., 2008). A satellite sketch is shown in Fig. 4. As a consequence, the preliminary mass budget for the satellite has changed the class from micro to mini satellite. For a 3-satellite constellation, the total dry mass of each satellite is $365 \mathrm{~kg}$ where the payload mass has been estimated $80 \mathrm{~kg}$. The total spacecraft launch mass has been estimated as $550 \mathrm{~kg}$ considering a margin of $15 \%$ and propellant of $130 \mathrm{~kg}$.

The core scientific payload of FloRad 2 consists of a conical scanning MMW radiometer, which uses the same concept of the SSM/I design. The current instrument configuration foresees a $0.35-\mathrm{m}$ reflector, sized according to required geometrical resolution. 
The FloRad2 system needs to accommodate the FLOROS GNSS receiver as well. The FloRad2 radio-occultation receiver is similar to the ROSA (Radio Occultation for the Sounding of Atmosphere) instrument (De Cosmo et al., 2008). ROSA is a geodetic-class GPS receiver and has 48 single-frequency channels, configured in order to have 16 L1CA/L1P/L2P dual-frequency channels for GPS frequencies L1 (1575.42 MHz) and L2 (1227.60 MHz). The ROSA antenna is made by 2 panels (velocity $\&$ anti-velocity antenna assembly) with 6 radiating elements with an overall size of about $100 \times 50 \mathrm{~cm}^{2}$. The accommodation of both FLOMIS and FLOROS is still an open issue.

The main Ground Station (using S-band for downlink/uplink) is planned to be located in Fucino (Italy). The Mission Operation Center (MOC), devoted to general management activities, is centralized and co-located with the Ground Station. The Mission Data Centre (MDC) is devoted to perform the ingestion and archiving of the data and Data Calibration \& Pre-processing and Distribution of Level L1b. The User Segment is devoted to all scientific data processing and product generation chain ensuring data storage and format to make them available to the users.

- VEGA launcher foreseeing one single launch directly in the selected orbit $(624 \mathrm{~km} \times 1224 \mathrm{~km})$ and one double lunch at an altitude of $2000 \mathrm{~km}$ in order to reduce the coasting phase.

- SOYUZ launcher foreseeing triple launch at an altitude of $2000 \mathrm{~km}$ in order to reduce the coasting phase.

The velocity increment for injecting the satellite in the final orbit is about $500 \mathrm{~m} / \mathrm{s}$. The duration of the deployment phase for 3 satellites is about 8 months for the second option. In case of the first option the duration of the whole phase is the interval time between the two launches plus 4 months of coasting phase. The interval time will be at least 2 months (minimum time between two launches).

\section{Conclusions}

The FloRad2 small-mission scientific requirements are aimed at the retrieval of hydrological properties of the troposphere, specifically water vapor profiles, cloud liquid content, rainfall and snowfall. In order to fulfill the goal of a short revisit time for meteorological monitoring purposes on a quasi-global scale with special focus on a specific target region, a Flower constellation (FC) of mini-satellites has been proposed. FC can offer several degrees of freedom in its design and its features have been shortly discussed. In this work, with respect to previous efforts (Marzano et al., 2009), the concept of the incremental FCs has been illustrated and their comparison with other orbital solutions discussed. The major result, as expected, is that IFC deployment strategy shows a revisit time increase, with respect to previous solutions, of the order of $50 \%$ in many cases. The information content of MMW radiometer multi-band channels has also been discussed, pointing out the trade-off between performance and complexity within the constraints of a low-cost mini-satellite platform. The overall error budget for various seasons and climatological regions shows that the FLOMIS selected channels can provide a valuable accuracy when aiming at the retrieval of humidity and hydrometeor profiles. Design elements of the mini-satellite system engineering, including the FLOMIS payload, and of the ground processing segment have been also illustrated.

The major areas of application of FloRad2 are: (i) numerical weather prediction (NWP); (ii) meteorological nowcasting; (iii) climate monitoring. In the context of numerical weather nowcasting FloRad2 measurements and products can be used both to better parameterize microphysical processes at the mesoscale, involving water vapor and hydrometeors and to validate thermo-dynamic and hydrometeorological fields. Precipitation nowcasting is a highpriority objective of civil protection applications. Time scales of nowcasting are usually shorter than $2 \mathrm{~h}$. The major impairment when trying to exploit LEO satellites is the low revisit time period which may be of the order of $12 \mathrm{~h}$ for scanning radiometers aboard a single sun-synchronous platform. The Flower constellation can minimize this revisit time, and in this respect can offer an unprecedented feature for LEO satellites.

Last but not least, the combined use of MMW radiometry and GNSS RO in FloRad2 mission can significantly contribute to establish and lengthen the climatic data record, especially that related to temperature and water vapor. In this respect, it is crucial to exploit the GNSS RO profiles as a means for external calibration of MMW radiometric observations. Finally, it should be envisaged to deploy a series of FloRad 2 constellations to ensure measurement continuity at fairly low cost and high performance.

Acknowledgements. The authors would like to thank the FloRad team (see Marzano et al., 2008) for providing suggestions and material for the present contribution on FloRad2. This work has been funded by the Agenzia Spaziale Italiana (ASI), Rome, Italy, under contract ASI n. I/018/08/0.

Edited by: S. C. Michaelides

Reviewed by: two anonymous referees 


\section{References}

Anthes, R. A., Bernahrdt, P. A., Chen, Y., Cucurull, L., Dymond, K. F., Ector, D., Healy, S. B., Ho, S.-P., Hunt, D. C., Kuo, Y.-H., Liu, H., Manning, K., Mccormick, C., Meehan, T. K., Randel, W. J., Rocken, C., Schreiner, W. S., Sokolovskiy, S. V., Syndergaard, S., Thompson, D. C., Trenberth, K. E., Wee, T.-K., Yen, N. L., and Zeng, Z:: The COSMIC/FORMOSAT-3 MISSION: Early Results, B. Am. Meteorol. Soc., doi:10.1175/BAMS-89-3-313, 2008.

Arriaga A.: Microwave Humidity Sounder (MHS) Simulations with a radiative transfer model, EUMETSAT Technical Memorandum n. 5, 2000.

Bauer, P. and Di Michele, S.: Mission Requirements for a postEPS Microwave Radiometer, Post-EPS EUMETSAT Contract No. EUM/CO/06/1510/PS, 2007.

Bormann, N., Kelly G., Bauer P., and Bell, W.: Assimilation and monitoring of SSMIS, AMSR-E and TMI data at ECMWF, Proceedings of the 15th International TOVS Study Conference, Maratea, Italy, October 2006.

De Cosmo, V., Galeazzi, C., Zin, A., Landenna, S., Granelli, G., Bandinelli, M., Perona, G., Notarpietro, R., Pierdicca, N., and Guerriero, L.: Development of ROSA Secon Generation Instrument for Radio Occultation and GNSS Scattterometry applications, Proceedings of 4th ESA Workshop on Satellite Navigation User Equipment Technologies NAVITECH 2008, 1-8, (Noordwijk, The Netherlands) Dec. 2008.

Dudhia, J.: A nonhydrostatic version for the Penn-State-NCAR mesoscale model: Validation test and simulation of an Atlantic cyclone and cold front, Mon. Weather Rev., 121, 1493-1513, 1993.

Faccani, C., Cimini, D., Marzano, F. S., and Ferretti, R.: Threedimensional variational assimilation of Special Sensor Microwave/Imager data into a mesoscale weather prediction model: a case study, Q. J. Royal Meteor. Soc., 133, 1295-1307, 2007.

Giorgi, F. and Mearns, L. O.: Regional climate modeling revisited. An Introduction to the special issue, J. Geophys. Res., 104, 6335-6352, 1999.

Goody, R., Aanderson, J., Karl, T., Balstad Miller, R., North, G., Simpson, J., Stephens, G., Washington, W.: Why monitor the climate?, B. Am. Meteorol. Soc., 83, 6, 873-878, 2002.

Gorbunov, M. E., Benzon, H.-H., Jensen, A. S., Lohmann, M. S., and Nielsen, A. S.: Comparative analysis of radio occultation processing approaches based on Fourier integral operators, Radio Sci., 39, RS6004, doi:10.1029/2003RS002916, 2004.

Ho, S.-P., Kuo Y.-H., Zeng Z., and Peterson T., 2007: A comparison of lower stratosphere temperature from microwave measurements with CHAMP GPS RO data, Geophys. Res. Lett., 34, L15701, doi:10.1029/2007GL030202, 2007.

Hou, A. Y., Skofronick-Jackson, G., Kummerow, C. D., and Shepherd, J. M.: Global precipitation measurement, edited by: Michaeleidis, M., Springer, 131-164, 2008.

Kidder, S. Q. and Vonder Haar, T. H.: Satellite meteorology: an introduction, Academic press, San Diego (CA), 1995.

Kursinski, E. R., Hajj, G. A., Hardy, K. R., Schofield, J. T., and Linfield, R.: Observing Earth's atmosphere with radio occultation measurements. J. Geophys. Res., 102, 23429-23465, 1997.

Larson, W. J. and Wertz, J. R.: Space Mission Analysis and Design - 3. Edn., Kluwer Academic Publishers, Boston, 1999.

Leroy, S., Anderson, J., and Dykema, J.: Climate benchmarking us- ing GNSS occultation, in Occultations for Probing Atmosphere and Climate II, edited by: Kirchengast, G., Foelsche, U., and Steiner, A., 287-301, Springer (NY), 2006.

Leroy, S. S., Anderson, J. G., and Ohring, G.: Climate signal detection times and constraints on climate benchmark accuracy requirements, J. Clim., 21, 4, 841-846, 2008.

Marzano, F. S., Cimini, D., Rossi, T., Mortari, D., Di Michele, S., and Bauer, P.: High-repetition Millimeter-wave Passive Remote Sensing of Humidity and Hydrometeor Profiles from Elliptical Orbit Constellations, J. Appl. Meteor. Clim., in press, 2010.

Marzano, F. S., Cimini, D., Memmo, A., Montopoli, M., Rossi, T., De Sanctis, M., Lucente, M., Mortari, D., and Di Michele, S.: Flower Constellation of Millimeter-wave Radiometers for Tropospheric Monitoring at Pseudo-geostationary Scale, IEEE T. Geosci. Remote Sens., 47(9), 3107-3122, 2009.

Marzano, F. S., Cimini, D., Rossi, T., De Sanctis, M., Lucente, M., Mortari, D., Oricchio, D., Varchetta, S., Pavia, P., Nassisi, A., Balduccini, M., Scorzolini, A., Reboa, L., Bruno, A., Perrotta, G., Giuliani, G., Giusto, R., and Di Michele, S.: FLORAD: Micro-satellite Flower Constellation of Millimeter-wave Radiometers for Atmospheric Remote Sensing, FLORAD PhaseA Final Report, ASI Contract n. I/018/08/0, Dec. 2008.

Marzano, F. S., Palmacci, M., Giuliani, G., Cimini, D., and Turk, J.: Multivariate statistical integration of satellite infrared and microwave radiometric measurements for rainfall retrieval at the geostationary scale, IEEE T. Geosci. Remote Sens., 42, 4, 10181032, 2004.

Mortari, D., Abdelkhalik, O., and Bruccoleri, C.: "Relative Flower Constellations with Applications for Planetary Explorations", Paper AAS 05-151, 15th AAS/AIAA Space Flight Mechanics Meeting, Copper Mountain, CO., 23-27 January, 2005.

Prabhakara, C., Iacovazzi R.Jr, Yoo J.-M., and Dalu G..: Global warming: Estimation from satellite observations, Geophys. Res. Lett., 27(21), 3517-3520, 2000.

Pulvirenti, L., Castracane, P., Marzano, F. S., Pierdicca, N., and d'Auria, G.: A Physical-Statistical Approach to Match Satellite Passive Microwave Retrieval to the Mediterranean climatology, IEEE T. Geosci. Remote Sens., 40, 4, 2271-2284, 2002.

Rizzi, R., Bauer, P., Crewell, S., Leroy, M., Mätzler, C., Menzel, W. P., Ritter, B., Russell, J. E., and Thoss, A.: AEG-CPL Position Paper - Cloud, Precipitation and Large Scale Land, Surface Imaging (CPL) Observational Requirements for Meteorology, Hydrology and Climate, EUMETSAT Post-EPS program, Version 1.k 06/03/06, 2006.

Rodgers, C. D.: Retrieval of atmospheric temperature and composition from remote measurements of thermal radiation, Rev. Geophys. Space Ge., 14(4), 609-624, 1976.

Schlüssel, P., Phillips, P., Accadia, C., Munro, R., Banfi, S., Wilson, J., and Sarlo, L.: Post-EPS Mission Requirements Document, EUMETSAT Document No. EUM/PEPS/REQ/06/0043, Issue v. 1J, 10 Jan. 2007.

Sokolovskiy, S., Kuo, Y.-H., Rocken, C., Schreiner, W. S., Hunt, D., and Anthes, R. A.: Monitoring the atmospheric boundary layer by GPS radio occultation signals recorded in the open-loop mode, Geophys. Res. Lett., 33, L12813, doi:10.1029/2006GL025955, 2006.

Sreerekha, T. R., Doherty, A. M., English, S. J., and Rayer, P. J.: Final Report on the Potential of Microwave Sounder $229 \mathrm{GHz}$ Channel, EUMETSAT Contract EUM/CO/07/4600000409/ CJA, 
April 22, 2008.

Stephens, G. L., Vane, D. G., Boain, R. J., Mace, G. G., Sassen, K., Wang, Z., Illingworth, A. J., O'Connor, E. J., Rossow, W. B., Durden, S. L., Miller, S. D., Austin, R. T., Benedetti, A., and Mitrescu, C.: The CloudSat mission and the A-Train: A new dimension of space-based observations of clouds and precipitation, B. Am. Meteor. Soc., 83, 1771-1790, 2002.

Stoffelen, A., Bonavita, M., Eyre, J., Goldberg, M., Järvinen, H., Serio, C., Thépaut, J.-N., and Wulfmeyer, V.: "AEG-AS Position Paper - Post-EPS Developments on Atmospheric Sounding and Wind Profiling", EUMETSAT Post-EPS program, Version 2.D 6/03/06, 2006.
Vespe, F., Perona, G., De Cosmo, V., Petitta, M., Materassi, M., Tartaglione, N., Zin, A., Notarpietro, R., Benedetto, C., Casotto, S., Speranza, A., and Sutera, A.: ROSA, The Italian Radio Occultation Mission Onboard the Indian OCEANSAT-2 satellite, in: New Horizons in Occultation Research, edited by: Steiner, A., Pirscher, B., Foelsche, U., and Kirchengast, G., 263-273, doi:10.1007/978-3-642-00321-9, 2009.

Ware, R, Rocken, C., Exner, M., Feng, D., Herman, B., Gorbunov, M., Hardy, K., Kuo, Y., Meehan, T., and Melbourne, W.: GPS sounding of the atmosphere from low Earth orbit: Preliminary results, B. Am. Meteor. Soc., 77, 19-40, 1996.

Wentz, F. J., Ricciardulli, L., Hilburn, K., and Mears, C.: How Much More Rain Will Global Warming Bring?, Science, 13, 317, 5835, 233-235, 2007. 